\title{
Immune mechanisms in alcoholic liver disease
}

\author{
Emanuele Albano $\cdot$ Matteo Vidali
}

Received: 23 July 2009/Accepted: 17 September 2009/Published online: 7 October 2009

(C) Springer-Verlag 2009

\begin{abstract}
Growing evidence indicates that inflammatory reactions play an important role in the pathogenesis of alcoholic liver disease (ALD). The implication of immunity in fueling chronic inflammation in ALD has emerged from clinical and experimental evidence showing the recruitment and the activation of lymphocytes in the inflammatory infiltrates of ALD and has received further support by the recent demonstration of a role of Th17 lymphocytes in alcoholic hepatitis. Nonetheless, the mechanisms by which alcohol triggers adaptive immune responses are still incompletely characterized. Patients with advanced ALD show a high prevalence of circulating IgG and T-lymphocytes towards epitopes derived from protein modification by hydroxyethyl free radicals (HER) and endproducts of lipid peroxidation. In both chronic alcohol-fed rats and heavy drinkers the elevation of IgG against lipid peroxidation-derived antigens is associated with an increased production of pro-inflammatory cytokines/chemokines and with the severity of histological signs of liver inflammation. Moreover, CYP2E1-alkylation by HER favors the development of anti-CYP2E1 auto-antibodies in a sub-set of ALD patients. Altogether, these results suggest that allo- and auto-immune reactions triggered by oxidative stress might contribute to fuel chronic hepatic inflammation during the progression of ALD.
\end{abstract}

Keywords Alcohol - Oxidative stress - Liver injury . Lipid peroxidation $\cdot$ Immunity

\footnotetext{
E. Albano $(\bowtie) \cdot$ M. Vidali

Department of Medical Sciences and Interdepartmental

Research Centre for Autoimmune Diseases,

University "Amedeo Avogadro" of East Piedmont,

Novara, Italy

e-mail: albano@med.unipmn.it
}

\section{Introduction}

Alcoholic liver disease (ALD) encompasses a broad spectrum of histological features ranging from steatosis with minimal parenchymal injury to steato-hepatitis and fibrosis/cirrhosis. While almost all heavy drinkers develop steatosis, only $10-35 \%$ of them show various degrees of alcoholic hepatitis and $8-20 \%$ progress to cirrhosis [83]. It is increasingly evident that chronic inflammation represents the driving force in the evolution of alcohol liver injury to steato-hepatitis and fibrosis/cirrhosis. Accordingly, the hepatic expression of pro-inflammatory cytokines precedes the development of histological signs of necro-inflammation in chronic alcohol-fed rats [59], while steato-hepatitis is associated with leucocyte focal infiltration and elevated circulating levels cytokines/chemokines such as TNF- $\alpha$, IL-1, IL-6, IL-8/CINC, and macrophage chemotatic protein-1 (MCP-1) [5, 19, 36, 40].

Several mechanisms might account for the stimulation of hepatic inflammation by ethanol. Early studies have proposed the involvement of an increased translocation of gut-derived endotoxins to the portal circulation [19, 54]. More recent experimental data demonstrate that ethanol itself also enhances the capacity of Kupffer cells to respond to pro-inflammatory stimuli. In particular, alcohol exposure up-regulates the expression of tool-like receptors [24] and enhances the signals controlling the production of proinflammatory cytokines/chemokines mediated by the nuclear transcription factors $\mathrm{kB}(\mathrm{NFkB})$ and Early Growth Response-1 (Erg-1) and by JNK, ERK, and p-38 protein kinases [40, 42, 47, 71]. Moreover, alcohol consumption increases the pro-inflammatory activity of liver Natural Killer T-cells (NKT) [44] and promotes the hepatocyte production of chemokines such as IL-8, MCP-1, and MIP-1 [20] that drive inflammatory cells to the hepatic 
parenchyma. Finally, a further contribution to inflammation in ALD might involve alcohol effects on osteopontin and the adipokines leptin, and adiponectin. Osteopontin is a cytokine produced by many tissues that enhances proinflammatory Th-1 responses and lymphocyte survival. An increase in the liver production of osteopontin has been associated with the extent of inflammation in alcohol-fed rodents [60] and hepatic osteopontin mRNA expression is higher in patients with alcoholic hepatitis than in heavy drinkers with fatty liver only [64]. Leptin and adiponectin originating from the adipose tissue are increasingly recognized to influence the inflammatory status of many tissues including the liver [74]. Leptin has a pro-inflammatory action and stimulates lymphocyte survival and proliferation favoring Th-1 reactions, while adiponectin blunts proinflammatory cytokine production and depresses the proliferation and activation of both B- and T-cells [33]. Alcohol has opposite effects on adipokines, as serum leptin is increased in patients with ALD [49], whereas chronic ethanol feeding decreases adiponectin secretion in the early phase of alcohol injury in rodents [28, 67] enhancing macrophage response to endotoxins [21].

Beside the activation of liver innate immunity, ALD pathogenesis also involves adaptive immunity. Early studies in ALD patients have detected circulating antibodies targeting alcohol-altered autologous hepatocytes [52]. In alcohol abusers, polyclonal hyper-production of gamma globulins is also frequent in association with $\operatorname{IgA}$ deposition in many tissues [36]. Moreover, ALD patients not rarely have signs of auto-immune reactions consisting in the presence of circulating antibodies directed against non-organ-specific and liver-specific auto-antigens [41]. In particular, anti-phospholipid antibodies can be observed in up to $80 \%$ of patients with alcoholic hepatitis or cirrhosis, but are not infrequent in heavy drinkers with milder liver damage [7, 10]. In agreement with these observations, histology reveals that the neutrophil-rich liver infiltrate characteristic of alcoholic hepatitis also contain both $\mathrm{CD} 8^{+}$ and $\mathrm{CD} 4^{+}$T-lymphocytes [9]. Furthermore, T-cells from both chronic alcohol-treated mice or alcohol abusers overexpress activation or memory markers and rapidly respond to $\mathrm{T}$-cell receptor stimulation by producing interferon- $\gamma$ (INF- $\gamma$ ) and TNF- $\alpha[65,66]$. The predominance of a Th- 1 pattern (high TNF- $\alpha$, INF- $\gamma$, IL-1) in cytokine production has also been observed in peripheral blood T-cells from active drinkers with or without ALD [35].

A new exciting input on the role of immunity in alcohol liver injury has come from a recent report demonstrating the activation of IL-17-producing T helper (Th17) lymphocytes in ALD and the specific contribution of IL-17 in promoting liver neutrophil infiltration during alcoholic hepatitis [37]. Th17 lymphocytes are a newly identified sub-set of effector helper T-cells distinct from Th- 1 and Th-2 CD $4{ }^{+} \mathrm{T}$-cells and characterized by the preferential production of IL-17, IL-21, and IL-22. [6, 53]. Th17 cells have a prominent role in controlling defensive mechanisms to bacterial infections mediating a crucial crosstalk with epithelial tissues [6]. Moreover, Th17 lymphocytes are increasingly recognized to play an important role in driving inflammation during the evolution of chronic inflammatory and autoimmune diseases including inflammatory bowel disease, psoriasis, rheumatoid arthritis, and multiple sclerosis [73].

\section{Oxidative stress as trigger of alcohol-induced immune reactions}

The mechanisms by which alcohol triggers adaptive immunity are still incompletely characterized. In their pioneering study Israel and colleagues [25] have shown that the adducts originating from acetaldehyde binding to hepatic proteins cause the production of specific antibodies when injected into experimental animals. The presence of anti-acetaldehyde antibodies has been subsequently confirmed in rats chronically exposed to alcohol as well as in alcoholic patients [30, 50]. Although the immunization of ethanol-fed guinea pigs with acetaldehyde-modified hemoglobin reproduces several features of alcoholic hepatitis [84], the interest for acetaldehyde-induced immune responses is hampered by the uncertainty regarding identity of the antigens involved and by the low specificity for ALD of anti-acetaldehyde antibodies [29].

Subsequent researches have demonstrated that, by interacting with proteins, hydroxyethyl free radicals (HER) generated during cytochrome P4502E1- (CYP2E1) dependent ethanol oxidation represent a source of antigens distinct from those originating from acetaldehyde [45]. Accordingly, anti-HER IgG have been detected in chronically ethanol-fed rats as well as in alcohol abusers [1,11]. Human anti-HER IgG recognize as main antigen HERmodified CYP2E1 [12], while the presence of anti-HER antibodies strictly correlates with CYP2E1 activity in both rodents and humans [2]. These observations, along with the demonstration of an oxidative stress-driven immunity in atherosclerosis and in several autoimmune diseases [32, 51], prompted us to investigate the possible implication of oxidative mechanisms in the immune responses associated with ALD.

It is well established that alcohol causes oxidative stress. Consistently, lipid peroxidation markers are increased in both the serum and the liver of ALD patients [3]. In this contest, we have observed that a large proportion (55-70\%) of patients with biopsy-proven alcoholic hepatitis and/or cirrhosis have elevated titers of circulating $\operatorname{IgG}$ towards proteins adducted by lipid peroxidation-derived products such as malondialdehyde (MDA), 4-hydroxynonenal, and 
oxidized arachidonic acid [46]. During alcohol intake the reaction between acetaldehyde, MDA, and the $\varepsilon$-amino group of protein lysine residues also generates condensation products named malonildialdehyde-acetaldehyde adducts (MAA) [72]. MAA adducts have been detected in the liver of ethanol-fed rats [72] and their formation is responsible for the increased titers of $\operatorname{IgG}$ recognizing MAA-modified proteins detectable in patients with advanced ALD [57]. Furthermore, oxidative stress likely contributes to the development of anti-phospholipid antibodies in alcohol abusers, as oxidized phospholipids, namely oxidized cardiolipin and phosphatidylserine, are the main antigens recognized by anti-phospholipid antibodies isolated from the sera of ALD patients [56, 76]. In about $35 \%$ of the patients with advanced ALD the presence of anti-MDA antibodies is associated with the detection of peripheral blood $\mathrm{CD}^{+}{ }^{+} \mathrm{T}$-cells responsive to MDA adducts, indicating the capability of oxidative stress to trigger both humoral and cellular immune responses [68]. Interestingly, ethanol stimulates oxidative stress-dependent immunity also in chronic hepatitis $\mathrm{C}$ (CHC). Indeed, even moderate alcohol intake by $\mathrm{CHC}$ patients increases in a dose-dependent manner the prevalence of $\mathrm{IgG}$ targeting lipid peroxidation-derived antigens [55]. This is consistent with recent experimental observations about the synergy between ethanol and hepatitis $\mathrm{C}$ virus in promoting oxidative liver injury [13].

\section{Possible mechanisms in the development of immune responses in alcoholic liver disease}

The interaction between alcohol and the immune systems is complex. It is known since long time that excessive alcohol consumption affects the innate and adaptive immunity increasing the susceptibility to infections and compromising tissue response to injury [69]. Moreover, both acute and chronic alcohol intake depresses antigen-presenting capability of monocytes and dendritic cells, affects the of expression co-stimulatory molecules, and reduces $\mathrm{T}$-cell proliferation [69].

In experiments performed with enteral alcohol-fed rats the hepatic expression of Th- 1 cytokines (TNF- $\alpha$, IL-12) m-RNAs shows a biphasic pattern with an early peak after 14 days of alcohol feeding and a secondary rise after 35 days [59]. Interestingly, all over the treatment alcohol suppresses the production of the Th- 2 cytokine IL- 4 and of the Th-2 regulator GATA3 [59], in accordance with the shift toward a Th-1 cytokine pattern observed in alcohol abusers [35]. The secondary increase in Th-1 cytokine RNAs is associated with the elevation of $\mathrm{Th}-1$ regulators T-bet and Stat-4 and histological evidence of necroinflammation [59]. Lipid peroxidation-derived antibodies are evident in concomitance with the late increase of Th-1 expression and the histological evidence of inflammatory infiltrates [59], while the anti-oxidant $N$-acetylcysteine reduces oxidative stress, lipid peroxidation-driven antibody production, and hepatic inflammation [58]. These observations suggest the possibility that, during the evolution of ALD, the increased production of pro-inflammatory cytokines/chemokines by endotoxin-activated Kupffer cells along with adipokine and osteopontin unbalances might overcome alcohol-dependent immune depression promoting the response of intraportal lymphoid follicles against antigens derived from oxidatively damaged hepatocytes [79]. This latter process is likely facilitated by the capacity of the scavenger receptors (SRA-1,2, CD36, SR-B1, LOX-1) and of some patter recognition receptors to recognize oxidized proteins and lipids [15]. Hepatic stellate cells (HSC) might represent an additional pathway for the presentation of oxidative stress-derived antigens to $\mathrm{CD}^{+}$ T-cell, as HSC are efficient antigen-presenting cells [81] and have the capability to internalize oxidation products [63]. Hepatic steatosis and oxidative stress have also been shown to lower regulatory T-cell (Tregs) population in the liver [39]. This might represent an additional factor in the development of immune response in ALD, as Tregs have key immuno-regulatory functions and their impairment is critical for lymphocyte activation against oxidized antigens from LDL during the evolution of atherosclerosis [23].

Little is known about the origin of anti-phospholipid antibodies often associated with ALD. In the recent years increasing evidence has linked defects in the disposal of apoptotic cells with the development of anti-phospholipid antibodies [31, 62]. Current view suggests that an impaired macrophage clearance of apoptotic corpses might lead to secondary necrosis of non-ingested cells with the release of intracellular components capable to activate inflammation. In this context, apoptotic cells might be ingested by immature dendritic cells, promoting their maturation and the presentation of self-antigens to T-lymphocytes [31, 62]. Accordingly, anti-phospholipid antibody production can be induced in mice by the immunization with syngenic apoptotic lymphocytes, but not with viable cells [8]. We have observed that anti-phospholipid antibodies from the sera of ALD patients bind to apoptotic, but not to living cells, by specifically targeting oxidized phosphatidylserine expressed on the cell surface [76]. Such specificity is consistent with recent reports showing that phosphatidylserine is oxidized during apoptosis before being exposed on the outer layer of cell plasma membranes [27]. As chronic alcohol intake stimulates hepatocyte apoptosis [48] and impairs the capacity of neighboring hepatocytes to dispose of apoptotic bodies [43], it is possible that the accumulation of apoptotic hepatocytes may lead to the development of anti-phospholipid antibodies in ALD. 
Oxidative stress and autoimmune reactions in alcoholic liver disease

As mentioned above, autoimmune reactions involving the presence of both non-organ-specific and liver-specific autoantibodies are a common feature in ALD. Among these latter, we have observed that alcohol-fed rats as well as about $40 \%$ of the patients with advanced ALD have circulating IgG directed against CYP2E1 [28, 77]. AntiCYP2E1 auto-antibodies from ALD patients are similar to those associated with halothane hepatitis and recognize at least two distinct conformational epitopes in the C-terminal portion of the molecule [78]. These epitopes are located in the molecule surface and account for the recognition by anti-CYP2E1 IgG of CYP2E1 expressed on the outer layer of the hepatocyte plasma membranes [78].

The breaching of self-tolerance toward anti-cytochrome P450 (CYP) isoenzyme is not rare in drug-induced hepatitis. This phenomenon has been explained by postulating that the binding of reactive drug metabolites to CYPs promotes humoral immune responses against the drugderived epitope(s) and favors at the same time the activation of normally quiescent auto-reactive lymphocytes towards the carrier CYP molecules [75]. ALD patients with anti-HER antibodies have a fourfold increased risk of developing anti-CYP2E1 auto-reactivity as compared with patients without anti-HER IgG [77]. This indicates that CYP2E1 alkylation by HER is involved in the development of ALD anti-CYP2E1 auto-antibodies.

Cytotoxic T lymphocyte associated antigen-4 (CTLA-4) is a membrane receptor expressed by activated T-lymphocytes and by $\mathrm{CD} 25^{+} \mathrm{CD} 4^{+}$Tregs that down-modulates T-cell-mediated responses to antigens [17]. Accordingly, CTLA-4 knockout mice show an expansion of $\mathrm{CD}^{+} /$ $\mathrm{CD}^{+} \mathrm{T}$ and B lymphocytes [16], while CTLA-4 polymorphisms in humans are genetic risk factors for several auto-immune diseases, including primary biliary cirrhosis and type-1 autoimmune hepatitis [17]. We have observed that CTLA-4 $\mathrm{Thr}^{17} \rightarrow$ Ala substitution increases by 3.8 fold the risk of developing anti-CYP2E1 IgG without influencing the formation of anti-HER antibodies [77]. ALD patients having both anti-HER IgG and mutated CTLA-4 show a prevalence of anti-CYP2E1 auto-reactivity 23-fold higher than those negative for both these factors [77]. Thus, in a sub set of ALD patients the antigenic stimulation by HER-modified CYP2E1 in combination with an impaired control of T-cell proliferation due to mutated CTLA-4 promotes the breaking of self-tolerance. The actual clinical significance of these observations needs further investigations. Preliminary data show that high titers of anti-CYP2E1 auto-antibodies correlate with the extension of lymphocyte infiltration and the frequency of apoptotic hepatocytes, suggesting that in a sub-set of
ALD autoimmune mechanisms might contribute to tissue injury.

\section{Possible role of immunity in the progression of alcohol liver damage}

Studies in atherosclerotic plaques have shown that the presentation of lipid peroxidation-derived antigens originating from oxidized low-density lipoproteins (LDL) to CD4 ${ }^{+}$T-cells leads to their Th-1 differentiation. On their turn, Th- 1 cells produce TNF- $\alpha$, and INF- $\gamma$ and express CD40 ligand that stimulate macrophages to release proinflammatory mediators, reactive oxygen species, and proteases further stimulating LDL oxidation and local inflammation [18]. A similar scenario might also occur in ALD where endotoxemia along with alcohol-mediated Kupffer cell activation promotes the production of proinflammatory cytokines priming hepatic lymphocytes to respond to lipid peroxidation-derived antigens. The cytokines released by activated $\mathrm{CD} 4^{+} \mathrm{T}$-cells can then further stimulate macrophage activation fueling in this way oxidative stress, parenchymal injury, hepatic inflammation, and collagen deposition.

Prior epidemiological prospective survey has shown an association between the presence of antibodies toward alcohol-modified hepatocytes and an increased risk of developing alcoholic liver cirrhosis [70]. At the same line, elevated titres of antibodies toward lipid peroxidation adducts and oxidized phospholipids are prevalent in heavy drinkers with alcoholic hepatitis and/or cirrhosis as compared to subjects without liver injury or with steatosis only [46, 56]. Lymphocyte-rich infiltrates are detectable in about $40 \%$ of ALD patients and their presence correlates with the extension of intralobular inflammation, peacemeal necrosis, and septal fibrosis [14]. Liver infiltrating T-lymphocytes in both ALD patients and alcohol-consuming rodents express markers associated with the activation/memory phenotypes and have an increased capacity to secrete pro-inflammatory cytokines [4]. Consistently, heavy drinkers with lipid peroxidation-derived antibodies have a fivefold higher prevalence of elevated plasma TNF$\alpha$ levels than alcohol abusers with these antibodies within the control range [80]. Moreover, in these subjects the combination of high TNF- $\alpha$ and lipid peroxidation-induced antibodies increases by 11-fold the risk of developing advanced ALD [80]. Altogether, these findings are consistent with a possible contribution of oxidative stressdriven immunity in sustaining hepatic inflammation in ALD. Interestingly, the elevation of the antibodies against lipid peroxidation-derived adducts is also an independent predictor of advanced fibrosis/cirrhosis in alcohol-consuming patients with $\mathrm{CHC}$ [81]. 
In conclusion, growing evidence indicates that alcoholinduced oxidative modifications of hepatic constituents trigger specific immune responses and, in combination with genetic predisposition, lead the breaking of the self-tolerance in the liver. The development of such adaptive immune responses is likely favored the alcohol-mediated stimulation of innate immunity and, on its turn, may contribute to maintain hepatic inflammation during the evolution of ALD. Nonetheless, in the progression of ALD to cirrhosis alcohol interactions with both the innate and adaptive immune systems are likely more complex. Indeed, recent reports indicate that chronic alcohol intake can promote fibrosis by interfering with the capacity of liver NK cells to selectively control the proliferation of early activated stellate cells $[22,26]$, whereas liver $\mathrm{CD}^{+} \mathrm{T}$-lymphocytes participate to the pro-fibrogenic activation of stellate cells [61].

Prospective clinical studies are required to dissect out the precise role of immune responses in the progression of ALD. If supported by other studies, the concept that acquired immunity is involved in alcohol hepatotoxicity might lead to the development of simple immunometric assays to discriminate ALD patients at risk of progressing to hepatitis and/or fibrosis. Moreover, the identification of alcohol abusers with a prominent immune component in their hepatic disease might lead to a targeted use of immune-suppressive therapy in ALD.

Acknowledgments The author's researches have been supported by grants from the Regional Government of Piedmont (Ricerca Sanitaria Finalizzata 2002, 2004 and Ricerca Scientifica Applicata 2004).

Conflict of interest statement The authors have no competing interests on the matter concerning the present manuscript.

\section{References}

1. Albano E, Clot P, Morimoto M, Tomasi T, Ingelman-Sundberg M, French S (1996) Role of cytochrome P4502E1-dependent formation of hydroxyethyl free radicals in the development of liver damage in rats intragastrically fed with ethanol. Hepatology 23:155-163

2. Albano E, French SW, Ingelman-Sundberg M (1999) Hydroxyethyl radicals in ethanol hepatotoxicity. Front Biosci 4:533-540

3. Albano E (2006) Alcohol, oxidative stress and free radical damage. Proc Nutr Soc 65:278-290

4. Batey RG, Cao Q, Gould B (2002) Lymphocyte-mediated liver injury in alcohol-related hepatitis. Alcohol 27:37-41

5. Bautista AP (2002) Neutrophilic infiltration in alcoholic hepatitis. Alcohol 7:17-21

6. Bettelli E, Korn T, Oukka M, Kuchroo VK (2008) Induction and effector functions of Th17 cells. Nature 493:1051-1057

7. Biron C, Lalloyer N, Tonnelot JL, Gris JC, Schved JF (1995) Anticardiolipin antibodies and acute alcoholic intoxication. Lupus 4:486-490

8. Chang MK, Binder CJ, Miller YI, Subbanagounder G, Silverman GJ, Berliner JA, Witztum JL (2004) Apoptotic cells with oxidation-specific epitopes are immunogenic and proinflammatory. J Exp Med 11:1359-1370

9. Chedid A, Mendenhall CL, Moritz TE, French SA, Chen TS, Morgan TR, Rosselle GA, Nemchausky BA, Taburro CH, Schiff ER, McClain GJ, Marsano LS, Allen JI, Samanta A, Weesner RE, Henderson WG, Veteran Affairs Cooperative Group 275 (1993) Cell-mediated hepatic injury in alcoholic liver disease. Gastroenterology 105:254-266

10. Chedid A, Chadalawada KR, Morgan TR, Moritz TE, Mendenhall CL, Hammond JB, Emblad PW, Cifuentes DC, Kwak JWH, Gilman-Sachs A, Beaman KD (1994) Phospholipid antibodies in alcoholic liver disease. Hepatology 20:1465-1471

11. Clot P, Bellomo G, Tabone M, Aricò S, Albano E (1995) Detection of antibodies against proteins modified by hydroxyethyl free radicals in patients with alcoholic cirrhosis. Gastroenterology 108:201-207

12. Clot P, Albano E, Elliasson E, Tabone M, Aricò S, Israel Y, Moncada Y, Ingelman-Sundberg M (1996) Cytochrome P4502E1 hydroxyethyl radical adducts as the major antigenic determinant for autoantibody formation among alcoholics. Gastroenterology 111:206-216

13. Choi J, Ou JHJ (2006) Mechanisms of liver injury III. Oxidative stress in the pathogenesis of hepatitis $\mathrm{C}$ virus. Am J Physiol 290:G847-G851

14. Colombat M, Charlotte F, Ratziu V, Poyard T (2002) Portal lymphocytic infiltrate in alcoholic liver disease. Hum Pathol 33:1170-1174

15. Chou MY, Hartvigsen K, Hansen LF, Fogelstrand L, Shaw PX, Boullier A, Binder CJ, Witztum JL (2008) Oxidation-specific epitopes are important targets of innate immunity. J Intern Med 263:479-488

16. Egen JG, Kuhns MS, Allison JP (2002) CTLA-4: new insights into its biological function and use in tumor immunotherapy. Nat Immunol 3:611-618

17. Gough SC, Walker LS, Sansom DM (2005) CTLA4 gene polymorphism and autoimmunity. Immunol Rev 204:102-115

18. Göran HK, Libby P (2006) Immune response in atherosclerosis: a double-edged sword. Nat Rev Immunol 6:508-519

19. Hines IN, Wheeler MD (2004) Recent advances in alcoholic liver disease III. Role of the innate immune response in alcoholic hepatitis. Am J Physiol 287:G310-G314

20. Horiguchi N, Wang L, Mukhopadhyay P, Park O, Jeong WI, Lafdil F, Osei-Hyiaman D, Moh A, Fu XY, Pacher P, Kunos G, Gao B (2008) Cell type-dependent pro-and anti-inflammatory role of signal transducer activator of transcription 3 in alcoholic liver injury. Gastroenterology 134:1148-1158

21. Huang H, Park PH, McMullen MR, Nagy LE (2008) Mechanisms for the anti-inflammatory effects of adiponectin in macrophages. J Gastroenterol Hepatol 23(suppl. 1):S50-S53

22. Gao B, Radaeva S, Jeong W (2007) Activation of NK cells inhibits liver fibrosis: a novel strategy to treat fibrosis. Expert Rev Gastroenterol Hepatol 1:173-180

23. George J (2008) Mechanisms of disease: the evolving role of regulatory $\mathrm{T}$ cells in atherosclerosis. Nat Clin Pract Cardiovasc Med 5:531-540

24. Gustot T, Lemmers A, Moreno C, Nagy N, Quertinmont E, Nicaise C, Franchimont D, Louis H, Devière J, Le Moine $O$ (2006) Differential liver sensitization to toll-like receptor pathway in mice with alcoholic fatty liver. Hepatology 43:989-1000

25. Israel Y, Hurwitz E, Niemelä O, Arnon R (1986) Monoclonal and polyclonal antibodies against acetaldehyde-containing epitopes in acetaldehyde-protein adducts. Proc Natl Acad Sci USA 83:79237927

26. Jeong W, Park O, Gao B (2008) Abrogation of anti-fibrotic effects of NK/INF- $\gamma$ contributes to alcohol acceleration of liver fibrosis. Gastroenterology 134:248-258 
27. Kagan VE, Borisenko GG, Serinkan BF, Tyurina YY, Tyurin VA, Jiang J, Liu SX, Shvedova AA, Fabisial JP, Uthsaisang W, Fadeel B (2003) Appetizing rancidity of apoptotic cells for macrophages: oxidation, externalization and recognition of phosphatidylserine. Am J Physiol 285:L1-L17

28. Kang L, Sebastian BM, Pritchard MT, Pratt BT, Previs SF, Nagy LE (2007) Chronic ethanol-induced insulin resistance is associated with macrophage infiltration into adipose tissue and altered expression of adiponectin. Alcohol Clin Exp Res 31:1581-1588

29. Klassen LW, Tuma D, Sorrell MF (1995) Immune mechanisms of alcohol-induced liver disease. Hepatology 22:355-357

30. Koskinas J, Kenna JG, Bird GL, Alexander GJM, Williams R (1992) Immunoglobulin A antibody to a 200-kilodalton cytosolic acetaldehyde adduct in alcoholic hepatitis. Gastroenterology 103:1860-1867

31. Krysko DV, D'Herde K, Vandenabeele P (2006) Clearance of apoptotic and necrotic cells and its immunological consequences. Apoptosis 11:1709-1726

32. Kurien BT, Scofield RH (2008) Autoimmunity and oxidatively modified antigens. Autoimmun Rev 7:567-573

33. Lago F, Dieguez C, Gomez-Reino J, Gualillo O (2007) Adipokines as emerging mediators of immune response and inflammation. Nat Rev Clin Pract Rheumatol 3:716-724

34. Laskin CA, Vidinis E, Blendis LM, Soloninka CA (1990) Autoantibodies in alcoholic liver disease. Am J Med 89:129-133

35. Laso JF, Madruga IJ, Orfao A (2002) Cytokines and alcohol liver disease. In: Sherman CDIN, Preedy VR, Watson RR (eds) Ethanol and the liver. Taylor and Francis, London, pp 206-219

36. Lavala J, Vietala J, Koivisto H, Jarvi K, Anttila P, Niemela O (2005) Immune responses to ethanol metabolites and cytokine profiles differentiate alcoholics with or without liver disease. Am J Gastroenterol 100:1303-1310

37. Lemmers A, Moreno C, Gustot T, Maréchal R, Degreé D, Demetter P, de Nadal P, Geerts A, Quertinmont E, Vercruysse V, Le Moine O, Devière J (2009) The interleukin-17 pathway is involved in human alcoholic liver disease. Hepatology 49:646-657

38. Lytton SD, Hellander A, Zhang-Gouillon ZQ, Stokkeland K, Bordone R, Aricò S, Albano E, French SW, Ingelman-Sundberg M (1999) Autoantibodies against cytochromes P-4502E1 and P4503A in alcoholics. Mol Pharmacol 55:223-233

39. Ma X, Hua J, Mohamood AR, Hamad AR, Ravi R, Li Z (2007) A high-fat diet and regulatory $\mathrm{T}$ cells influence susceptibility to endotoxin-induced liver injury. Hepatology 46:1519-1529

40. Mandrekar P, Szabo G (2009) Signalling pathways in alcoholinduced liver inflammation. J Hepatol 50:1258-1266

41. McFarlane IG (2000) Autoantibodies in alcoholic liver disease. Addict Res 5:141-151

42. McMullen MR, Pritchard MT, Wang Q, Millward CA, Croniger CM, Nagy LE (2005) Early growth response-1 transcription factor is essential for ethanol-induced fatty liver in mice. Gastroenterology 128:2066-2076

43. McVicker BL, Tuma DJ, Kubik JA, Hindemith AM, Baldwin CR, Casey CA (2002) The effect of ethanol on asialoglycoprotein receptor-mediated phagocytosis of apoptotic cells by rat hepatocytes. Hepatology 36:1478-1487

44. Minagawa M, Deng Q, Liu ZX, Tzukamoto H, Dennert G (2004) Activated natural killer $\mathrm{T}$ cells induce liver injury by Fas and tumor necrosis factor- $\alpha$ during alcohol consumption. Gastroenterology 126:1387-1399

45. Moncada C, Torres V, Vargese E, Albano E, Israel Y (1994) Ethanol-derived immunoreactive species formed by free radical mechanisms. Mol Pharmacol 46:786-791

46. Mottaran E, Stewart SF, Rolla R, Vay D, Cipriani V, Moretti MG, Vidali M, Sartori M, Rigamonti C, Day CP, Albano E (2002) Lipid peroxidation contributes to immune reactions associated with alcoholic liver disease. Free Radic Biol Med 32:38-45
47. Nagy LE (2003) Recent insights into the role of the innate immune system in the development of alcoholic liver disease. Exp Biol Med 228:882-890

48. Natori S, Rust C, Stadheim LM, Srinivasan A, Burgan LJ, Gores GJ (2001) Hepatocyte apoptosis is a pathological feature of human alcoholic hepatitis. J Hepatol 24:248-253

49. Naveau S, Perlemuter G, Chaillet M, Raynard B, Balian A, Beuzen F, Portier A, Galanaud P, Emilie D, Chaput JC (2006) Serum leptin in patients with alcoholic liver disease. Alcohol Clin Exp Res 30:1422-1428

50. Niemelä O, Klajner F, Orrego H, Vidinis E, Blendis L, Israel Y (1987) Antibodies against acetaldehyde-modified protein epitopes in human alcoholics. Hepatology 7:1210-1214

51. Palinski W, Witztum JL (2000) Immune response to oxidative neoepitopes on LDL and phospholipids modulate the development of atherosclerosis. J Intern Med 247:171-180

52. Paronetto F (1993) Immunologic reactions in alcoholic liver disease. Semin Liver Dis 13:183-195

53. Ouyang W, Kolls JK, Zheng Y (2008) The biological functions of $\mathrm{T}$ helper 17 cell effector cytokines in inflammation. Immunity 28:454-467

54. Rao R (2009) Endotoxemia and gut barrier dysfunction in alcoholic liver disease. Hepatology 50:638-644

55. Rigamonti C, Mottaran E, Reale E, Rolla R, Cipriani V, Capelli F, Boldorini R, Vidali M, Sartori M, Albano E (2003) Moderate alcohol consumption increases oxidative stress in patients with chronic hepatitis C. Hepatology 38:42-49

56. Rolla R, Vay D, Mottaran E, Parodi M, Sartori M, Rigamonti C, Bellomo G, Albano E (2001) Anti-phospholipid antibodies associated with alcoholic liver disease specifically recognize oxidized phospholipids. Gut 49:852-859

57. Rolla R, Vay D, Mottaran E, Parodi M, Traverso N, Aricò S, Sartori M, Bellomo G, Klassen LW, Thiele GM, Tuma DJ, Albano E (2000) Detection of circulating antibodies against malondialdehyde-acetaldehyde adducts in patients with alcoholinduced liver disease. Hepatology 31:878-884

58. Ronis MJJ, Butura A, Sampey BP, Prior RL, Korourian S, Albano E, Ingelman-Sundberg M, Petersen DR, Badger TM (2005) Effects of $\mathrm{N}$-acetyl cysteine on ethanol-induced hepatotoxicity in rats fed via total enteral nutrition. Free Radic Biol Med 39:619-630

59. Ronis MJ, Butura A, Korourian S, Shankar K, Simpson P, Badeaux J, Albano E, Ingelman-Sundberg M, Badger TM (2008) Cytokine and chemokine expression associated with steatohepatitis and hepatocyte proliferation in rats fed ethanol via total enteral nutrition. Exp Biol Med 233:344-355

60. Ramaiah SH, Ritting S (2007) Role of osteopontin in regulating hepatic inflammatory responses and toxic liver injury. Expert Opin Drug Metab Toxicol 3:519-526

61. Safadi R, Ohta M, Alvarez CE, Fiel MI, Bansal M, Mehal WZ, Friedman SL (2004) Immune stimulation of hepatic fibrogenesis by CD8 cells and attenuation by transgenic interleukin-10 from hepatocytes. Gastroenterology 127:870-882

62. Savill J, Dransfield I, Gregory C, Haslett C (2002) A blast from the past: clearance of apoptotic cells regulates immune responses. Nat Rev Immunol 2:965-975

63. Schneiderhan W, Schmid-Kotsas A, Zhao J, Grunert A, Nusslaer A, Weidenbach H, Menke A, Schmid RM, Adler G, Bachem MG (2001) Oxidized low-density lipoproteins bind to the scavenger receptor, CD36, of hepatic stellate cells and stimulate extracellular matrix synthesis. Hepatology 34:729-737

64. Seth D, Gorrell MD, Cordoba S, McCaughan GW, Haber PS (2006) Intrahepatic gene expression in human alcoholic hepatitis. J Hepatol 45:306-320

65. Song K, Coleman RA, Zhu X, Alber C, Ballas ZK, Waldschmidt TJ, Cook RT (2002) Chronic ethanol consumption by mice results in activated splenic T cells. J Leukoc Biol 72:1109-1116 
66. Song K, Coleman RA, Alber C, Ballas ZK, Waldschmidt TJ, Mortari F, LaBrecque DR, Cook RT (2001) TH1 cytokine response of CD57+ T-cell subsets in healthy controls and patients with alcoholic liver disease. Alcohol 24:155-167

67. Song Z, Zhou Z, Deaciuc I, Chen T, McClain CJ (2008) Inhibition of adiponectin production by homocysteine: a potential mechanism for alcoholic liver disease. Hepatology 47:867-879

68. Stewart SF, Vidali M, Day CP, Albano E, Jones DEJ (2004) Oxidative stress as a trigger for cellular immune response in patients with alcoholic liver disease. Hepatology 39:197-203

69. Szabo G, Mandrekar P (2009) A recent perspective on alcohol, immunity and host defence. Alcohol Clin Exp Res 33:220-232

70. Takase S, Tsutsumi M, Kawahara H, Takada N, Takada A (1993) The alcohol-altered liver membrane antibody and hepatitis $\mathrm{C}$ virus infection in the progression of alcoholic liver disease. Hepatology 17:9-13

71. Thakur V, Pritchard MT, McMullen MR, Wang Q, Nagy LE (2006) Chronic ethanol feeding increases activation of NADPH oxidase by liposaccharide in rat Kupffer cells: role of increased reactive oxygen in LPS-stimulated ERK1/2 activation and TNFalpha production. J Leukoc Biol 79:1348-1356

72. Thiele GM, Freeman TK, Klassen LW (2004) Immunological mechanisms of alcoholic liver disease. Semin Liver Dis 24:273287

73. Tesmer LA, Lundy SK, Sarkar S, Fox DA (2008) Th17 cells in human disease. Immunol Res 223:87-113

74. Tilg H, Moschen AR (2006) Adipokines: mediators linking adipose tissue, inflammation and immunity. Nat Rev Immunol 6:4772-4783

75. Van Pelt FNAM, Straub P, Manns MP (1995) Molecular basis of drug-induced immunological liver injury. Semin Liver Dis $15: 283-300$
76. Vay D, Rigamonti C, Vidali M, Mottaran E, Alchera E, Occhino G, Sartori M, Albano E (2006) Anti-phospholipid antibodies associated with alcoholic liver disease target oxidized phosphatidylserine on apoptotic cell plasma membranes. J Hepatol 44:183-189

77. Vidali M, Stewart SF, Rolla R, Daly AK, Chen Y, Mottaran E, Jones DEJ, Leathart JB, Day CP, Albano E (2003) Genetic and epigenetic factors in autoimmune reactions toward cytochrome P4502E1 in alcoholic liver disease. Hepatology 37:277-285

78. Vidali M, Hidestrand M, Eliasson E, Mottaran E, Reale E, Rolla R, Occhino G, Albano E, Ingelman-Sundberg M (2004) Use of molecular simulation for mapping conformational CYP2E1 epitopes. J Biol Chem 279:50949-50955

79. Vidali M, Stewart SF, Albano E (2008) Interplay between oxidative stress and immunity in the progression of alcohol-mediated liver injury. Trends Mol Med 14:63-71

80. Vidali M, Hietala J, Occhino G, Ivaldi A, Sutti S, Niemelä O, Albano E (2008) Immune responses against oxidative stressderived antigens are associated with increased circulating Tumor Necrosis Factor- $\alpha$ and accelerated liver damage in heavy drinkers. Free Radic Biol Med 45:306-311

81. Vidali M, Occhino G, Ivaldi A, Rigamonti C, Sartori M, Albano E (2008) Combination of oxidative stress and steatosis is a risk factor for fibrosis in alcohol-drinking patients with chronic hepatitis C. Am J Gastroenterol 103:147-153

82. Winau F, Quack C, Darmoise A, Kaufmann SH (2008) Starring stellate cells in liver immunology. Curr Opin Immunol 20:68-74

83. Yip WW, Burt AD (2006) Alcoholic liver disease. Semin Diagn Pathol 23:149-160

84. Yokoyama H, Ishii H, Nagata S, Kato S, Kamegaya K, Tsuchiya M (1993) Experimental hepatitis induced by ethanol after immunization with acetaldehyde adducts. Hepatology 17:14-19 